\title{
Development of an explicit tool assessing potentially inappropriate medication use in Hong Kong elder patients
}

\author{
Huanyu Zhang ${ }^{1}$, Eliza LY Wong ${ }^{1 *}$ (D), Eng-kiong Yeoh ${ }^{1}$ and Bosco HM Ma²
}

\begin{abstract}
Background: Potentially inappropriate medication (PIM) use has adverse effects on health, particularly in elder patients. Various country-specific explicit criteria have been developed to measure the appropriateness of prescribing worldwide. However, it is difficult to apply the criteria developed from other regions to measure and guide the local prescribing practice in Hong Kong. This study aims to develop a Hong Kong-specific PIM assessing tool from previously published criteria and validate this tool using the modified Delphi method.
\end{abstract}

Methods: A disease-oriented Hong Kong-specific preliminary PIM list was developed based on nine sets of reference criteria selected from a literature review. Any medication or medication class appeared in at least two sets of the reference criteria as well as its related medical conditions were selected as PIM candidates. After examining the availability of PIM candidates by the Hong Kong Hospital Authority drug formulary, the Hong Kong-specific preliminary PIM list was validated by a two-round of modified Delphi process. Eight experts from different specialties were invited to rate the degree of inappropriateness of each PIM candidate using a five-point Likert scale. The experts were also encouraged to propose therapeutic alternatives and new PIM candidates not covered by the preliminary PIM list. The PIM candidates that the expert panel didn't reach consensus on were excluded from the final Hong Kong-specific PIM list.

Results: After two rounds of the Delphi process, eight PIM candidates remained questionable and thus were excluded from the PIM list. The final Hong Kong-specific PIM list included a total of 164 statements applicable to older adults aged 65 years or above, among which 77 were under PIMs independent of diagnoses, and 87 were under PIMs considering specific medical conditions.

Conclusions: The Hong Kong-specific PIM list can be used as a quality measure and an educational tool to improve the local prescribing quality. Further studies should validate its association with adverse health outcomes in clinical and research settings.

Keywords: Potentially inappropriate medication, Explicit criteria, Delphi method, Older adults, Hong Kong

\footnotetext{
* Correspondence: lywong@cuhk.edu.hk

${ }^{1}$ Centre for Health Systems and Policy Research, The Jockey Club School of Public Health and Primary Care, Faculty of Medicine, The Chinese University of Hong Kong, Prince of Wales Hospital, Shatin, New Territories, Hong Kong Full list of author information is available at the end of the article
}

(c) The Author(s). 2021 Open Access This article is licensed under a Creative Commons Attribution 4.0 International License, which permits use, sharing, adaptation, distribution and reproduction in any medium or format, as long as you give appropriate credit to the original author(s) and the source, provide a link to the Creative Commons licence, and indicate if changes were made. The images or other third party material in this article are included in the article's Creative Commons licence, unless indicated otherwise in a credit line to the material. If material is not included in the article's Creative Commons licence and your intended use is not permitted by statutory regulation or exceeds the permitted use, you will need to obtain permission directly from the copyright holder. To view a copy of this licence, visit http://creativecommons.org/licenses/by/4.0/. The Creative Commons Public Domain Dedication waiver (http://creativecommons.org/publicdomain/zero/1.0/) applies to the data made available in this article, unless otherwise stated in a credit line to the data. 


\section{Background}

Potentially inappropriate medication (PIM) use, generally occurring when patients are prescribed drugs with an unfavorable balance of benefits and risks, is a preventable problem [1]. PIM use can lead to adverse drug events, which elevate the risk of poor quality of life and high health care costs [2]. Older adults are particularly at high risk for PIM use due to physiologic changes in pharmacokinetics and pharmacodynamics [3]. Moreover, a great number of older adults suffer from comorbid diseases and are prescribed multiple medications [4]. Several studies revealed that polypharmacy, which referred to the use of five and more prescribed drugs at the same time, was associated with greater risk of PIM use [3, 5 , 6]. In Hong Kong, people aged 65 years or older accounted for $17.9 \%$ of the total population in 2018 and this proportion was projected to be $33.7 \%$ by 2066 [7]. To present a wider perspective, in 2019, the proportions of older adults in the populations of North America and Europe were estimated to be 16.4 and $18.8 \%$, respectively [8]. Therefore, it is important to identify PIMs among the older adults in Hong Kong to minimize drug-related issues and improve health outcomes.

With an aging population, appropriateness of prescribing has become a public health concern worldwide and thus, various tools have been developed to assess the quality of prescribing. These measures can be generally categorized into explicit (criterion-based) and implicit (judgment-based) tools [9]. Explicit tools are typically firm standards developed from published literature, expert opinions and consensus techniques [10]. They are usually drug or disease oriented and can be applied to large samples of people to measure the appropriateness of prescribing from a population level [11]. By contrast, implicit tools can evaluate the appropriateness of prescribing from an individual level depending on a health professional's judgement. However, it is time-consuming to apply implicit tools in clinical practice and they have low reliability and reproducibility $[8,9]$. As a systematic approach, explicit tools are therefore more favored in real world practice.

Older adults are usually excluded from clinical trials, thus lacking evidence on balancing risks and benefits of therapeutic agents in this population [12]. Under this circumstance, consensus techniques such as Delphi methods, are acceptable for use in developing explicit assessing tools despite its limitations of subjective evaluations [13]. The first explicit tool for assessing PIM use in older adults was the Beers criteria created based on Delphi methods in the US in 1991 [14] and updated on a three-year cycle since 2012 [15]. Although the Beers criteria were widely used to assess the quality of prescribing globally, several researchers indicated the difficulty of adapting the Beers criteria into the local situation because of contextual differences in terms of licensed drugs, clinical practice and health system regulations [16-18]. Accordingly, it is unlikely to transfer explicit indicators from one country to another without going through a process of adaption and modification [7]. In recent years, tools for assessing prescribing appropriateness have intensified in different countries across Europe, North America and Asia [19]. However, limited overlap could be observed between different PIM lists and some of them were lack of special considerations of use and therapeutic alternatives to PIMs [19].

In Hong Kong, we recently conducted a study to assess the prevalence of PIM use in elder patients aged 65 years and older visiting general outpatient clinics, using the main subsets of the 2015 Beers criteria. The prevalence estimates ranged from $55.6 \%$ in 2006 to $47.5 \%$ in 2014 , which were relatively higher than those reported in western countries [6, 20, 21], ranging from 2.9 to $43.3 \%$ assessed by the Beers criteria. We also found that only $60 \%$ of the statements from the Beers criteria that we addressed in the study were available in the drug formulary from Hospital Authority (HA), which is a statutory body to manage all public hospitals and clinics in Hong Kong. To enhance the comprehensiveness of quality criteria to evaluate medication use in the context of Hong Kong, it is necessary to develop a Hong Kong-specific explicit assessing tool. To our knowledge, up to now, no Hong Kong-specific PIM lists have been established or validated yet. The aim of this study was to develop a Hong Kong-specific PIM assessing tool on the basis of published criteria in the literature and input from the local context using the modified Delphi method.

\section{Methods}

\section{Development of a preliminary PIM list}

The first step in developing the Hong Kong-specific PIM criteria was to establish a preliminary drug list based on existing criteria in the literature. A literature search was conducted to identify explicit tools assessing PIM use on the PubMed database from January 1991 to April 2019 internationally and consequently, 40 sets of validated explicit criteria were identified. Explicit criteria that 1) applied to the general population aged 65 years and older, 2 ) used the literature review on safety and efficacy of drug use as an evidence base, and 3) described the methods of development and validation for the criteria, were taken into account. Regarding the criteria that were updated occasionally, only the latest versions of PIM lists were considered and the early versions of the criteria were eliminated from the study. Consequently, the following nine sets of explicit criteria were included as reference criteria in the current study: the McLeod criteria [22], the Rancourt criteria [23], the Lindblad criteria [24], the Laroche criteria [17], the Winit-Watjana 
criteria [25], the Norwegian General Practice [26], the PRISCUS criteria [12], the version 2 of the Screening Tool of Older Person's Prescription (STOPP) [27], and the 2015 version of the Beers criteria [28].

The structures of the nine sets of reference criteria were heterogeneous, with the classification system of criteria statements as disease-oriented or/and drugoriented. The evaluated aspects of the reference criteria are summarized in Table 1 . The most common evaluated aspects in the nine sets of reference criteria included generally avoided drugs independent of diagnoses (7/9), dosage (6/9), disease-drug interactions (6/9), and drug-drug interactions (7/9). After reviewing the structures of the reference criteria, the evaluation of dosage was found to be rarely classified as a separate category of PIM use in the reference criteria. Furthermore, the lists of drug-drug interactions in the reference criteria were mostly selective and not comprehensive. Therefore, the current study was intended to exclude drug-drug interactions and develop a disease-oriented preliminary PIM list. The structure of the Hong Kong-specific preliminary PIM list was formulated using two common categories of PIMs from the reference criteria, namely, generally avoided drugs independent of diagnoses, and disease-drug interactions.

Based on the structure of the preliminary PIM list, the operational definitions of PIM use in the current study are described as follows: 1) medications or medication classes that should be generally avoided independent of diagnosis or conditions and 2) medications or medication classes that should not be used in older adults known to have specific medical conditions. Other evaluated aspects of PIM use including dosage, duration of therapy, alternative therapies and special considerations of use were supplemented by experts' comments during the Delphi process. Following the operational definition of PIM use in this study, seven sets of reference criteria included generally avoided drugs independent of diagnoses and six sets of criteria included disease-drug interactions. After extracting all related statements from the reference criteria, 279 medications/classes under generally avoided drugs independent of diagnoses and 115 medications/classes considering specific medical conditions were identified.

To prepare a manageable amount of PIM statements for further evaluations in the Delphi process, any medication or medication class appeared in at least two sets of the reference criteria (if appeared in two sets of criteria, one of which must be the Beers criteria) and its related medical conditions were selected from relevant reference criteria as candidate PIMs for each category of PIM use. We used the Beers criteria to select medications that appeared in two sets of criteria because the Beers criteria were considered as the golden standard for PIM assessment and many country-specific explicit criteria were developed based on the Beers criteria [19]. The availability of candidate PIMs was examined by the Hospital Authority (HA) drug formulary issued in April 2018. The candidates not covered by the HA drug formulary were excluded from the preliminary PIM list. Meanwhile, all the individual medications belonging to each medication class were also identified from the HA drug formulary. The medications/classes were identified by the Anatomical Therapeutic Chemical (ATC) classification system codes to enhance the standardization of PIM candidates. After applying the inclusion and

Table 1 Summary of evaluated aspects in the nine sets of reference criteria

\begin{tabular}{|c|c|c|c|c|c|c|c|c|c|}
\hline $\begin{array}{l}\text { List } \\
\text { name }\end{array}$ & Country & $\begin{array}{l}\text { Independent } \\
\text { of diagnosis } \\
\text { (7/9) }\end{array}$ & $\begin{array}{l}\text { Dosage } \\
(6 / 9)\end{array}$ & $\begin{array}{l}\text { Duration of } \\
\text { therapy }(4 / \\
\text { 9) }\end{array}$ & $\begin{array}{l}\text { Disease-drug } \\
\text { interactions } \\
(6 / 9)\end{array}$ & $\begin{array}{l}\text { Drug-drug } \\
\text { interactions } \\
(7 / 9)\end{array}$ & $\begin{array}{l}\text { Duplication } \\
\text { (3/9) }\end{array}$ & $\begin{array}{l}\text { Alternative } \\
\text { therapies (4/ } \\
\text { 9) }\end{array}$ & $\begin{array}{l}\text { Special } \\
\text { consideration of } \\
\text { use }(4 / 9)\end{array}$ \\
\hline $\begin{array}{l}\text { McLeod } \\
\text { criteria }\end{array}$ & Canada & & & $\checkmark$ & $\checkmark$ & $\checkmark$ & & $\checkmark$ & $\checkmark$ \\
\hline $\begin{array}{l}\text { Rancourt } \\
\text { criteria }\end{array}$ & Canada & $\checkmark$ & $\checkmark$ & $\checkmark$ & & $\checkmark$ & $\checkmark$ & & \\
\hline $\begin{array}{l}\text { Lindblad } \\
\text { criteria }\end{array}$ & USA & & & & $\checkmark$ & & & & \\
\hline $\begin{array}{l}\text { Laroche } \\
\text { criteria }\end{array}$ & France & $\checkmark$ & $\checkmark$ & & $\checkmark$ & $\checkmark$ & $\checkmark$ & $\checkmark$ & \\
\hline $\begin{array}{l}\text { Winit- } \\
\text { Watjana } \\
\text { criteria }\end{array}$ & Thailand & $\checkmark$ & & & $\checkmark$ & $\checkmark$ & & & \\
\hline NORGEP & Norway & $\checkmark$ & $\checkmark$ & & & $\checkmark$ & & & \\
\hline PRISCUS & Germany & $\checkmark$ & $\checkmark$ & & & & & $\checkmark$ & $\checkmark$ \\
\hline $\begin{array}{l}\text { STOPP } \\
\text { version } 2\end{array}$ & Ireland & $\checkmark$ & $\checkmark$ & $\checkmark$ & $\checkmark$ & $\checkmark$ & $\checkmark$ & $\checkmark$ & $\checkmark$ \\
\hline $\begin{array}{l}\text { Beers } \\
\text { criteria }\end{array}$ & USA & $\checkmark$ & $\checkmark$ & $\checkmark$ & $\checkmark$ & $\checkmark$ & & & $\checkmark$ \\
\hline
\end{tabular}


exclusion criteria, the final Hong Kong-specific preliminary PIM list included 168 candidates, 78 of which were developed under PIMs independent of diagnoses, and 90 were developed under PIMs considering specific medical conditions for further questioning in the Delphi process.

\section{Delphi method}

The preliminary PIM list was validated by a two-round modified Delphi process. Experts from different specialties were recruited by invitation emails and personal communication, all involved with practice or research in medication issues for elder patients for at least five years. A face-to-face meeting was also convened with six potential experts one by one to brief them on the study background and objectives. After the briefing meeting, five experts decided to participate in the project. Invitation emails were also disseminated to the Hong Kong Geriatric Society (HKGS). Four geriatric physicians from the HKGS replied for a further in-person meeting and three of them finally decided to take part in the study after the meeting. Overall, a total of eight (80\%) experts agreed in participating in the project seeking to develop the Hong Kong-specific PIM list. On the basis of the preliminary PIM list, a five-point Likert scale was designed to construct the questionnaire for collecting experts' ratings and comments during the Delphi process. The questionnaire was examined for wording and content validity by three qualified experts.

The first round of the Delphi process began in August, 2019. The experts were asked to rate the degree of inappropriateness of each candidate statement from a score of 1 (strongly disagree) to 5 (strongly agree). A score of 3 was neutral or undecided. Furthermore, the experts were encouraged to provide comments on any exception or restriction in terms of indication, dose, route of administration, or therapy duration to make each candidate statement more accurate. They were also asked to propose therapeutic alternatives to the PIMs independent of diagnoses and suggest new PIM candidates not included in the questionnaire.

After the first round of questioning, the experts' answers were presented as median with interquartile ranges (IQR) for each candidate PIM. The statements with medians $\geq 3.5$ and $\mathrm{IQR} \leq 1.5$ were included in PIM use, whereas the statements with medians $<3.0$ were excluded from PIM use [25]. The statements with $3.0 \leq$ medians $<3.5$ or IQR $>1.5$ were regarded as questionable PIMs that required further evaluations in the second round along with the new candidate PIMs suggested by the expert panel [25]. The second round of the Delphi process was conducted in October, 2019. All the experts received the second-round questionnaire together with the panel's ratings and comments from the first round. The experts' feedbacks in the second round were evaluated using the same procedure.

\section{Results}

Eight experts participated in the first round of the Delphi process. One expert with a pharmacy background quit during the second round of questioning due to illness. The characteristics of eight experts are shown in Table 2. All the experts worked in public hospitals or universities, and the majority of them were males. The expert panel had specialties in geriatric medicine, pharmacy, family medicine, and internal medicine, and half of them were geriatric physicians. Most of the experts had a working experience related to medication issues for elder patients longer than 10 years $(50 \%$ longer than 20 years).

In the first round of the Delphi process, 117 (69.6\%) candidate statements were designated as PIM use whereas $8(4.8 \%)$ statements were designated as nonPIM use and dropped from the study. Forty-three (25.6\%) candidates were classified as questionable PIM use, which required further evaluations in the second round. Furthermore, three new indications of the PIMs listed in the preliminary list were suggested by the expert panel to be included in the second round of rating. According to the ATC classification system, terazosin is classified as a urological drug while prazosin and doxazosin are classified as antihypertensives; however, they all belong to alpha-adrenoreceptor antagonists and can be indicated as either a urological or an antihypertensive drug based on the expert panel's comments. The

Table $\mathbf{2}$ Characteristics of the expert panel

\begin{tabular}{ll}
\hline Characteristics & No. of experts (\%) \\
\hline Male & $6(75.0)$ \\
Gorking field(s) & $6(75.0)$ \\
Pharmacy & $3(37.5)$ \\
General practice/Family medicine & $1(12.5)$ \\
Internal medicine & $1(12.5)$ \\
Profession & \\
Pharmacists & $3(37.5)$ \\
Geriatric physician & $4(50.0)$ \\
General practitioner & $1(12.5)$ \\
Years of experience related to medication issues for elder patients \\
$5 \sim 10$ years & $1(12.5)$ \\
$11 \sim 15$ years & $3(37.5)$ \\
$>$ 20 years & $4(50.0)$ \\
Working place & $2(25.0)$ \\
University & $6(75.0)$ \\
Public hospital &
\end{tabular}


indications not included in the first round of questioning were rated again in the second round. The expert panel also proposed nine new PIM candidates not incorporated in the preliminary list, seven of which were under PIMs independent of diagnoses, and two were under PIMs considering specific medical conditions. Furthermore, the experts' comments in terms of rationales, restrictions, and exceptions for each PIM candidate were consolidated and expanded based on the reference criteria. Consequently, a total of 55 candidates, including 44 in the current list plus 12 new suggestions, was brought forward to the next round of the Delphi voting.

In the second round of questioning, $47(85.5 \%)$ candidates were rated as PIM use while $8(14.5 \%)$ candidates remained questionable PIM use (Table 3). Among the eight questionable candidates, one candidate was rated with the IQR value greater than 1.5 whereas the other seven candidates were rated with the median value lower than 3.5. The eight questionable PIM candidates were excluded from the Hong Kong-specific PIM criteria due to the large discrepancy or low median score based on the experts' ratings. The flowchart of the Delphi process is shown in Fig. 1. After two rounds of the Delphi process, the final Hong Kong-specific PIM list included 164 statements, among which 77 were under PIMs independent of diagnoses (Table 4), and 87 were under PIMs considering specific medical conditions (Table 5). The full list of medications or medication classes with ATC codes included in PIMs considering specific medical conditions are presented in Additional file 1. The main concerns and the possible therapeutic alternatives for the Hong Kong-specific PIM list are presented in Additional file 2.

\section{Discussion}

This study developed and validated the first explicit tool for assessing PIM use in older adults in Hong Kong. Many country-specific explicit tools have been developed by including all the PIMs defined by several previously published criteria and validated in the local context [29-31]. However, the current study selected the most common PIMs from the nine sets of reference criteria published in North America, Europe, and Asia, which enhanced the generalizability of the Hong Kongspecific PIM criteria for international comparisons. Furthermore, new PIM statements, which were not included in the previously published criteria, were also integrated into the Hong Kong-specific PIM list based on the local clinical experience.

Among the 164 statements classified as PIM use in the Hong Kong-specific PIM list, experts had agreed with approximately $70 \%$ of them after the first round of questioning. This result may indicate that strong evidence could prove the pharmacological inappropriateness of these statements in older adults or better therapeutic alternatives exist in the public sector in Hong Kong. By contrast, some of the statements were not designated as PIM use until the second round of rating, such as certain hypnotics and sedatives (zopiclone and zolpidem), which may be because the expert panel believed that these drugs could be used with low dose or in short term depending on individualized situations in the context of Hong Kong. The proton pump inhibitors (PPIs) were designated as non-PIM use after the first round of questioning in this study. It is probably because the experts think PPIs can be used with caution among elder patients as long as the therapy duration is not longer than 8 weeks. Another reason could be the experts believe the misuse of PPIs is not particularly problematic for older adults, while the development of the Hong Kong-specific PIM criteria is unique to the aging population.

After two rounds of the Delphi process, eight PIM candidates still remained questionable PIMs. Several reasons accounted for the questionable PIMs that the panel didn't reach consensus on. First, some of the PIM

Table 3 Questionable PIMs that the expert panel did not reach consensus

\begin{tabular}{llll}
\hline PIMs independent of diagnoses & & & Median \\
\hline Medication class & Medication & 3 & IQR \\
Antithrombotic agents & Dipyridamole & 4 & $2.50 \sim 3.50$ \\
Antidepressants & Dosulepin (dothiepin) & 3 & $2.50 \sim 4.50$ \\
& Fluoxetine & 3 & $2.00 \sim 3.50$ \\
Analgesics & Acetaminophen & 3 & $2.50 \sim 4.00$ \\
& Methyl salicylate topical ointment & $3.00 \sim 4.00$ \\
PIMs considering specific medical conditions & & Median & 3 \\
Disease/Syndrome & Medication class/Medication & 3 & $3.00 \sim 4.00$ \\
Blood clotting disorders & Clopidogrel & 3 & $3.00 \sim 4.00$ \\
Falls & Dipyridamole & 3 & $3.00 \sim 4.00$ \\
\hline
\end{tabular}




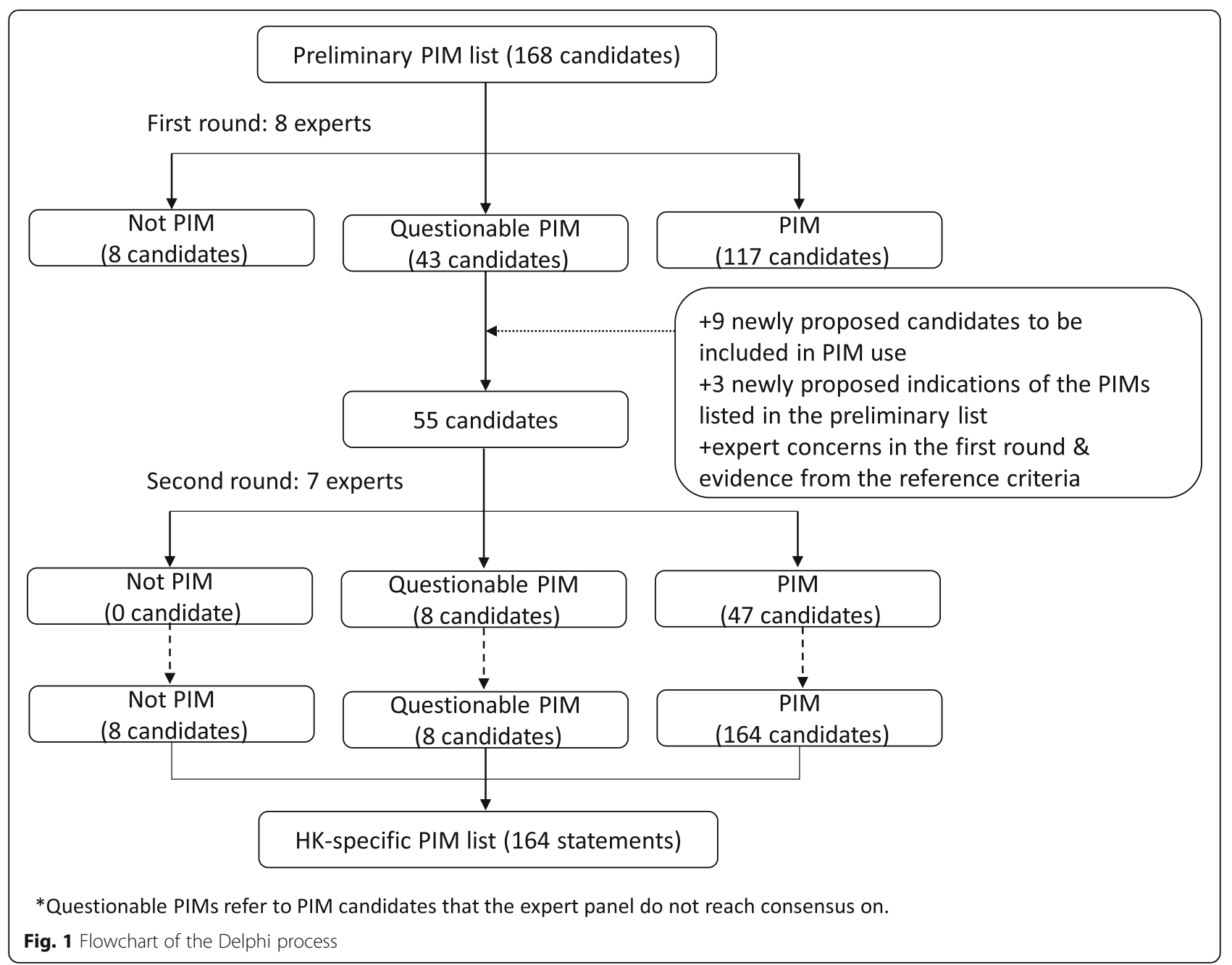

candidates were regarded as inappropriate use in older adults in the reference criteria but no therapeutic alternatives existed in the HA drug formulary (e.g. fluoxetine as an antidepressant). Second, the expert panel decided that some of the questionable PIMs were acceptable for use in older adults as long as the dosage was not excessive (e.g. acetaminophen as an analgesic). Third, several disease-drug interaction candidates were rated as undecided or neutral because the expert panel felt it was necessary to balance the benefits and risks of the potentially inappropriate drugs depending on the individuals' circumstances. According to the previous studies conducted in other countries $[13,14]$, questionable statements that experts did not reach consensus on should be generally considered as appropriate for use in elder patients. Hence, the questionable PIM candidates were excluded from the Hong Kong-specific PIM criteria in the current study.

Apart from the preliminary PIM list, the panel also proposed nine new PIM candidates, seven of which were eventually designated as PIM use. However, some of these newly suggested statements were only applicable to a subgroup of older adults, such as bisphosphonates to bedbound patients, and lacked of evidence from reference criteria. Therefore, more research findings are necessary to justify the inappropriateness of these seven PIM statements in the future updates.

Compared with the Beers criteria, the Hong Kongspecific PIM criteria are more user-friendly to guide the local prescribing practice. All the individual medications that appeared in the Hong Kong-specific criteria were listed with ATC classification codes, making it easier for health professionals to identify active substances. Therapeutic alternatives to PIMs independent of diagnoses are also offered to health professionals for reference. To be externally valid, explicit indicators for PIM use with adequate validity should be linked with adverse health outcomes. Some previous studies showed a positive association between the Beers criteria and multiple patient-related outcomes including hospitalization, mortality, falls and functional decline [32]. The relationship between the Hong Kong-specific PIM criteria and 
Table 4 Hong Kong-specific potentially inappropriate medication list: independent of diagnosis (results of the Delphi process)

\begin{tabular}{|c|c|c|c|c|}
\hline Medication class & Medications & ATC code & Median & IQR \\
\hline \multirow[t]{3}{*}{ Antispasmodics } & Propantheline & $\mathrm{A} 03 \mathrm{AB} 05$ & 5 & $3.50 \sim 5.00$ \\
\hline & Atropine & A03BA01 & 5 & $3.50 \sim 5.00$ \\
\hline & Metoclopramide & A03FA01 & 3.5 & $2.75 \sim 4.00$ \\
\hline Long-acting sulfonylureas & Glipizide & A10BB07 & 4 & $4.00 \sim 4.50$ \\
\hline Cardiac glycosides & Digoxin & C01AA05 & 4 & $3.00 \sim 4.00$ \\
\hline \multirow[t]{2}{*}{ Antiarrhythmics } & Disopyramide & C01BA03 & 4 & $3.00 \sim 4.00$ \\
\hline & Amiodarone & $\mathrm{C} 01 \mathrm{BD} 01$ & 4 & $3.00 \sim 4.00$ \\
\hline \multirow[t]{5}{*}{ Antihypertensives } & Methyldopa & $\mathrm{CO} 2 \mathrm{AB}$ & 4 & $3.75 \sim 4.25$ \\
\hline & Clonidine & C02AC01 & 4 & $3.75 \sim 4.25$ \\
\hline & Prazosin & C02CA01 & 4 & $2.75 \sim 4.00$ \\
\hline & Doxazosin & C02CA04 & 4 & $4.00 \sim 5.00$ \\
\hline & Terazosin & G04CA03 & 4 & $4.00 \sim 5.00$ \\
\hline Calcium channel blockers & Nifedipine & C08CA05 & 4 & $4.00 \sim 5.00$ \\
\hline Androgens & Testosterone & G03BA03 & 4 & $4.00 \sim 4.00$ \\
\hline \multirow[t]{2}{*}{ Estrogens } & Estradiol & G03CA03 & 3.5 & $3.00 \sim 4.00$ \\
\hline & Tibolone & G03CX01 & 3.5 & $3.00 \sim 4.00$ \\
\hline \multirow[t]{4}{*}{ Urologicals } & Oxybutynin & G04BD04 & 3.5 & $2.75 \sim 4.00$ \\
\hline & Terazosin & G04CA03 & 4 & $4.00 \sim 4.00$ \\
\hline & Doxazosin & C02CA04 & 4 & $4.00 \sim 4.00$ \\
\hline & Prazosin & C02CA01 & 4 & $4.00 \sim 4.00$ \\
\hline Antibacterials for systemic use & Nitrofurantoin & J01XE01 & 4 & $4.00 \sim 5.00$ \\
\hline \multirow[t]{3}{*}{ Antiinflammatory and antirheumatic products } & Indometacin & M01AB01 & 4 & $3.00 \sim 4.00$ \\
\hline & Sulindac & M01AB02 & 4 & $3.00 \sim 4.00$ \\
\hline & Diclofenac & M01AB05 & 4 & $4.00 \sim 4.00$ \\
\hline \multirow[t]{8}{*}{ Antiinflammatory and antirheumatic products } & Ketorolac & M01AB15 & 4 & $3.75 \sim 4.00$ \\
\hline & Piroxicam & M01AC01 & 4 & $3.75 \sim 4.00$ \\
\hline & Meloxicam & M01AC06 & 4 & $3.75 \sim 4.00$ \\
\hline & Ibuprofen & M01AE01 & 4 & $4.00 \sim 4.00$ \\
\hline & Naproxen & M01AE02 & 4 & $3.00 \sim 4.00$ \\
\hline & Mefenamic acid & M01AG01 & 4 & $3.00 \sim 4.00$ \\
\hline & Celecoxib & M01AH01 & 4 & $4.00 \sim 4.00$ \\
\hline & Etoricoxib & M01AH05 & 4 & $4.00 \sim 4.00$ \\
\hline \multirow[t]{3}{*}{ Muscle relaxants } & Orphenadrine & M03BC01 & 4 & $4.00 \sim 4.00$ \\
\hline & Baclofen & M03BX01 & 4 & $4.00 \sim 4.00$ \\
\hline & Tolperisone & M03BX04 & 4 & $3.50 \sim 4.00$ \\
\hline \multirow[t]{9}{*}{ Antipsychotics } & Chlorpromazine & N05AA01 & 4 & $4.00 \sim 4.25$ \\
\hline & Prochlorperazine & N05AB04 & 3.5 & $2.75 \sim 4.00$ \\
\hline & Trifluoperazine & N05AB06 & 4 & $3.75 \sim 4.25$ \\
\hline & Haloperidol & N05AD01 & 4 & $4.00 \sim 4.00$ \\
\hline & Ziprasidone & N05AE04 & 4 & $3.50 \sim 4.00$ \\
\hline & Pimozide & N05AG02 & 4 & $4.00 \sim 4.50$ \\
\hline & Clozapine & N05AH02 & 3.5 & $3.00 \sim 4.00$ \\
\hline & Olanzapine & N05AH03 & 4 & $3.50 \sim 4.00$ \\
\hline & Quetiapine & N05AH04 & 4 & $3.50 \sim 4.00$ \\
\hline
\end{tabular}


Table 4 Hong Kong-specific potentially inappropriate medication list: independent of diagnosis (results of the Delphi process) (Continued)

\begin{tabular}{|c|c|c|c|c|}
\hline Medication class & Medications & ATC code & Median & IQR \\
\hline & Risperidone & N05AX08 & 4 & $3.50 \sim 4.00$ \\
\hline & Aripiprazole & N05AX12 & 4 & $3.50 \sim 4.00$ \\
\hline & Paliperidone & N05AX13 & 4 & $3.50 \sim 4.00$ \\
\hline \multirow[t]{8}{*}{ Benzodiazepines } & Clonazepam & N03AE01 & 4 & $2.75 \sim 4.25$ \\
\hline & Diazepam & N05BA01 & 4 & $2.75 \sim 4.25$ \\
\hline & Chlordiazepoxide & N05BA02 & 4 & $2.75 \sim 4.25$ \\
\hline & Lorazepam & N05BA06 & 4 & $3.50 \sim 5.00$ \\
\hline & Bromazepam & N05BA08 & 4 & $2.75 \sim 4.25$ \\
\hline & Clobazam & N05BA09 & 4 & $2.75 \sim 4.25$ \\
\hline & Alprazolam & N05BA12 & 3.5 & $2.75 \sim 4.00$ \\
\hline & Nitrazepam & N05CD02 & 4 & $2.75 \sim 4.25$ \\
\hline \multirow[t]{3}{*}{ Benzodiazepines } & Flunitrazepam & N05CD03 & 4 & $2.75 \sim 4.25$ \\
\hline & Triazolam & N05CD05 & 3.5 & $2.75 \sim 4.00$ \\
\hline & Midazolam & N05CD08 & 3.5 & $2.75 \sim 4.00$ \\
\hline Anxiolytics & Hydroxyzine & N05BB01 & 4 & $3.00 \sim 4.00$ \\
\hline \multirow[t]{2}{*}{ Hypnotics and sedatives } & Zopiclone & N05CF01 & 4 & $3.00 \sim 4.50$ \\
\hline & Zolpidem & N05CF02 & 4 & $3.00 \sim 4.50$ \\
\hline \multirow[t]{6}{*}{ Antidepressants } & Imipramine & N06AA02 & 4 & $4.00 \sim 5.00$ \\
\hline & Clomipramine & N06AA04 & 4 & $4.00 \sim 5.00$ \\
\hline & Trimipramine & N06AA06 & 4 & $4.00 \sim 5.00$ \\
\hline & Amitriptyline & N06AA09 & 4 & $3.50 \sim 5.00$ \\
\hline & Nortriptyline & N06AA10 & 4 & $3.50 \sim 5.00$ \\
\hline & Doxepin & N06AA12 & 4 & $3.75 \sim 5.00$ \\
\hline \multirow[t]{5}{*}{ Antihistamines } & Chlorpheniramine & R06AB04 & 3.5 & $2.75 \sim 4.25$ \\
\hline & Cyproheptadine & R06AX02 & 3.5 & $2.75 \sim 4.25$ \\
\hline & Dexchlorpheniramine & R06AB02 & 3.5 & $2.75 \sim 4.25$ \\
\hline & Diphenhydramine & R06AA02 & 4 & $2.75 \sim 4.25$ \\
\hline & Promethazine & R06AD02 & 3.5 & $2.75 \sim 4.25$ \\
\hline \multicolumn{5}{|c|}{ New PIMs suggested by the expert panel } \\
\hline \multirow[t]{3}{*}{ Analgesics } & Acetaminophen & N07BC02 & 3 & $2.50 \sim 4.00$ \\
\hline & Methyl salicylate topical ointment & A06AG01 & 3 & $3.00 \sim 4.00$ \\
\hline & Methadone & A06AD15 & 4 & $4.00 \sim 4.50$ \\
\hline \multirow[t]{2}{*}{ Laxatives } & Sodium phosphate enema & M05BA & 4 & $4.00 \sim 4.00$ \\
\hline & Polyethylene glycol electrolyte powder & N02AA59 & 4 & $3.50 \sim 4.00$ \\
\hline
\end{tabular}

patient-related health outcomes needs to be validated externally in different settings in future studies.

The Hong Kong-specific PIM criteria can be used to assess prescribing patterns in Hong Kong and to educate patients and health professionals on appropriate drug use. The statements listed in the Hong Kong-specific PIM criteria should be generally avoided in older adults aged 65 years or above from a population level. However, the criteria cannot replace a clinician's final decision- making from an individual level. If patients are not responsive to the therapeutic alternatives, the potentially inappropriate medications included in the criteria could also be prescribed for elder patients with close monitoring and dose adjustments under specific circumstances. The development of the Hong Kong-specific PIM criteria is intended to raise awareness of difficulties of pharmacotherapy for elder patients. Because all the medications included in the Hong Kong-specific PIM list are 
Table 5 Hong Kong-specific potentially inappropriate medication list: considering specific medical conditions (results of the Delphi process)

\begin{tabular}{|c|c|c|c|}
\hline Disease/Syndrome & Medication class/Medication & Median & IQR \\
\hline \multicolumn{4}{|l|}{ Blood and blood-forming organs } \\
\hline \multirow[t]{2}{*}{ Blood clotting disorders } & NSAIDs & 4 & $3.00 \sim 4.00$ \\
\hline & Asprin & 3.5 & $2.75 \sim 4.00$ \\
\hline \multicolumn{4}{|l|}{ Cardiovascular } \\
\hline \multirow[t]{6}{*}{ Syncope } & AChEls & 4 & $3.00 \sim 4.00$ \\
\hline & Thioridazine & 4 & $4.00 \sim 4.25$ \\
\hline & TCAs & 4 & $3.75 \sim 5.00$ \\
\hline & Alpha-adrenoreceptor antagonists & 4 & $3.75 \sim 4.25$ \\
\hline & Chlorpromazine & 4 & $4.00 \sim 5.00$ \\
\hline & Methyldopa & 4 & $4.00 \sim 4.25$ \\
\hline \multirow[t]{3}{*}{ Heart failure } & Thiazolidinediones & 4 & $4.00 \sim 4.25$ \\
\hline & NSAIDs & 4 & $3.75 \sim 4.25$ \\
\hline & Nondihydropyridine CCBs & 4 & $3.50 \sim 4.50$ \\
\hline \multirow[t]{2}{*}{ Heart block } & TCAs & 5 & $4.00 \sim 5.00$ \\
\hline & Beta blocking agents & 5 & $4.00 \sim 5.00$ \\
\hline Cardiac arrhythmia & Antipsychotics & 4 & $3.00 \sim 4.00$ \\
\hline \multicolumn{4}{|l|}{ Central nervous system } \\
\hline \multirow[t]{5}{*}{ Delirium } & Sedative hypnotics & 4 & $3.00 \sim 4.25$ \\
\hline & Benzodiazepines & 4 & $4.00 \sim 5.00$ \\
\hline & Anticholinergics & 4 & $4.00 \sim 4.25$ \\
\hline & Antipsychotics & 3.5 & $2.75 \sim 4.00$ \\
\hline & Corticosteroids & 3.5 & $3.00 \sim 4.00$ \\
\hline \multirow[t]{2}{*}{ Parkinson disease } & Antipsychotics & 3.5 & $3.00 \sim 4.00$ \\
\hline & Metoclopramide & 4 & $4.00 \sim 4.25$ \\
\hline \multirow[t]{4}{*}{ Dementia/ Cognitive impairment } & Benzodiazepines & 4 & $2.75 \sim 4.25$ \\
\hline & Anticholinergics & 4 & $3.50 \sim 4.25$ \\
\hline & TCAs & 4 & $3.50 \sim 4.25$ \\
\hline & Antipsychotics & 3.5 & $2.75 \sim 4.00$ \\
\hline \multirow[t]{6}{*}{ Falls } & Sedative hypnotics & 4 & $3.00 \sim 4.25$ \\
\hline & Thioridazine & 4 & $3.75 \sim 4.25$ \\
\hline & Benzodiazepines & 4 & $4.00 \sim 4.50$ \\
\hline & TCAs & 4 & $3.50 \sim 5.00$ \\
\hline & Antipsychotics & 4 & $3.50 \sim 4.25$ \\
\hline & Opioids & 4 & $4.00 \sim 4.50$ \\
\hline \multirow[t]{3}{*}{ Epilepsy/Seizures } & Bupropion & 4 & $3.75 \sim 4.00$ \\
\hline & Thioridazine & 4 & $4.00 \sim 4.00$ \\
\hline & Antipsychotics & 3.5 & $3.00 \sim 4.00$ \\
\hline Behavioural and psychological symptoms of dementia & Antipsychotics & 3.5 & $2.50 \sim 4.00$ \\
\hline Depression & Methyldopa & 4 & $3.75 \sim 4.25$ \\
\hline Lewy body disease & Antipsychotics & 4 & $3.75 \sim 4.00$ \\
\hline Sleep apnea syndrome & Benzodiazepines & 4 & $3.75 \sim 4.00$ \\
\hline \multicolumn{4}{|l|}{ Circulatory system } \\
\hline Postural hypotension & TCAs & 4.5 & $4.00 \sim 5.00$ \\
\hline
\end{tabular}


Table 5 Hong Kong-specific potentially inappropriate medication list: considering specific medical conditions (results of the Delphi process) (Continued)

\begin{tabular}{|c|c|c|c|}
\hline Disease/Syndrome & Medication class/Medication & Median & IQR \\
\hline & Dihydropyridine CCBs & 4 & $3.50 \sim 4.00$ \\
\hline & Alpha-adrenoreceptor antagonists & 4.5 & $3.75 \sim 5.00$ \\
\hline & Chlorpromazine & 4.5 & $4.00 \sim 5.00$ \\
\hline Hypertension & NSAIDs & 4 & $4.00 \sim 4.50$ \\
\hline Raynaud disease & Beta blocking agents & 4 & $3.75 \sim 4.00$ \\
\hline Postural hypotension & Thioridazine & 4 & $4.00 \sim 4.25$ \\
\hline Venous thromboembolism & Oestrogens & 4 & $4.00 \sim 4.25$ \\
\hline \multicolumn{4}{|c|}{ Endocrine, nutritional and metabolic system } \\
\hline Hypokalaemia & Thiazide diuretics & 4 & $3.75 \sim 4.00$ \\
\hline Hyponatraemia & SSRIS & 3.5 & $3.00 \sim 4.00$ \\
\hline Hyponatraemia & Thiazide diuretics & 4 & $3.75 \sim 4.00$ \\
\hline Hyperkalaemia & AChEls & 3.5 & $3.00 \sim 4.00$ \\
\hline Hypercalcaemia & Thiazide diuretics & 4 & $3.00 \sim 4.00$ \\
\hline Diabetes & Corticosteroids & 4 & $4.00 \sim 4.00$ \\
\hline Diabetic hypoglycemia & Beta blocking agents & 3.5 & $3.00 \sim 4.00$ \\
\hline \multicolumn{4}{|l|}{ Eye and adnexa } \\
\hline \multirow[t]{2}{*}{ Glaucoma } & Anticholinergics & 4 & $4.00 \sim 4.00$ \\
\hline & TCAs & 4 & $4.00 \sim 5.00$ \\
\hline \multicolumn{4}{|l|}{ Gastrointestinal System } \\
\hline \multirow[t]{5}{*}{ Chronic constipation } & Anticholinergics & 4 & $4.00 \sim 4.25$ \\
\hline & TCAs & 4 & $4.00 \sim 5.00$ \\
\hline & Methyldopa & 4 & $3.00 \sim 4.00$ \\
\hline & Opioids & 4 & $3.75 \sim 4.25$ \\
\hline & CCBs & 3.5 & $3.00 \sim 4.00$ \\
\hline \multicolumn{4}{|l|}{ Kidney and urinary tract } \\
\hline Chronic kidney disease & NSAIDs & 5 & $4.75 \sim 5.00$ \\
\hline \multirow[t]{3}{*}{ Peptic ulcer disease } & NSAIDs (Non-COX-2 selectvie agents) & 4.5 & $4.00 \sim 5.00$ \\
\hline & Aspirin & 3.5 & $3.00 \sim 4.00$ \\
\hline & Corticosteroids & 4 & $4.00 \sim 4.00$ \\
\hline \multirow[t]{3}{*}{ Lower urinary tract symptoms } & Anticholinergics & 4 & $3.50 \sim 4.25$ \\
\hline & TCAs & 4 & $4.00 \sim 4.25$ \\
\hline & Chlorpromazine & 4 & $4.00 \sim 4.25$ \\
\hline \multirow[t]{3}{*}{ Urinary retention } & Anticholinergics & 4 & $4.00 \sim 5.00$ \\
\hline & TCAs & 4 & $4.00 \sim 5.00$ \\
\hline & Chlorpromazine & 4 & $4.00 \sim 5.00$ \\
\hline \multirow[t]{2}{*}{ Benign prostatic hyperplasia } & Anticholinergics & 4 & $3.75 \sim 4.25$ \\
\hline & TCAs & 4 & $4.00 \sim 4.25$ \\
\hline \multirow[t]{2}{*}{ Urinary incontinence } & TCAs & 4 & $3.00 \sim 4.00$ \\
\hline & Alpha-adrenoreceptor antagonists in women & 4 & $4.00 \sim 4.00$ \\
\hline Prostate adenoma & Anticholinergics & 3.5 & $3.00 \sim 4.25$ \\
\hline \multicolumn{4}{|c|}{ Musculoskeletal system and connective tissue } \\
\hline Gout & Thiazide diuretics & 4 & $3.75 \sim 4.00$ \\
\hline Osteoarthritis & Corticosteroids & 4 & $4.00 \sim 4.00$ \\
\hline
\end{tabular}


Table 5 Hong Kong-specific potentially inappropriate medication list: considering specific medical conditions (results of the Delphi process) (Continued)

\begin{tabular}{|c|c|c|c|}
\hline Disease/Syndrome & Medication class/Medication & Median & IQR \\
\hline Osteoporosis & Corticosteroids & 3.5 & $3.00 \sim 4.00$ \\
\hline \multicolumn{4}{|l|}{ Neoplasms } \\
\hline Breast cancer & Oestrogens & 4 & $4.00 \sim 4.25$ \\
\hline \multicolumn{4}{|l|}{ Respiratory system } \\
\hline \multirow[t]{3}{*}{ Chronic obstructive pulmonary disease } & Benzodiazepines & 3.5 & $3.00 \sim 4.25$ \\
\hline & Beta blocking agents & 3.5 & $3.00 \sim 4.00$ \\
\hline & Corticosteroids & 4 & $3.00 \sim 4.00$ \\
\hline \multirow[t]{2}{*}{ Asthma } & Benzodiazepines & 4 & $4.00 \sim 4.50$ \\
\hline & Beta blocking agents & 4 & $3.75 \sim 4.25$ \\
\hline Respiratory failure & Benzodiazepines & 4 & $3.00 \sim 4.25$ \\
\hline \multicolumn{4}{|l|}{ New PIMs suggested by the expert panel } \\
\hline Severe active liver diseases & Acetaminophen & 4 & $4.00 \sim 4.00$ \\
\hline Transplanted organ and tissue status & Fluoroquinolones & 4 & $4.00 \sim 4.00$ \\
\hline
\end{tabular}

covered by the HA drug formulary, they can be integrated easily into the HA computer system and updated on a cycle.

The limitation of the Hong Kong-specific PIM criteria was that the preliminary PIM list was derived from previously published criteria with insufficient evidence on drug use from recent findings. The current study was intended to develop a diseaseoriented PIM list and only two categories of PIM criteria were considered. Thus, expanding the Hong Kong-specific PIM criteria and including other categories of PIM criteria such as drug-drug interactions or duplications in future updates is necessary. Furthermore, the expert panel consisted mainly of physicians and pharmacists from public hospitals and the newly developed criteria were only applicable in the public sector. Thus, to facilitate the effects of the Hong Kong-specific PIM list, the selection of PIM candidates and the expert panel from the private sector should also be considered in the development of future versions of PIM lists.

\section{Conclusions}

In conclusion, the Hong Kong-specific PIM list can be applied as a quality measure and an educational tool to improve the appropriateness of prescribing in the local context. It can provide physicians and pharmacists with practical advice to make better therapeutic decisions. Future studies should focus on validating the association between the Hong Kong-specific PIM assessment tool and adverse health outcomes in clinical and research settings.

\section{Supplementary Information}

The online version contains supplementary material available at https://doi. org/10.1186/s12877-021-02024-0.

Additional file 1:. The full list of medications or medication classes with ATC codes included in PIMs considering specific medical conditions

Additional file 2:. Main concerns and possible therapeutic alternatives of the Hong Kong-specific potentially inappropriate medication list

\section{Abbreviations}

PIM: Potentially Inappropriate Medication Use; HA: Hospital Authority; ATC: Anatomical Therapeutic Chemical; IQR: Interquartile ranges

\section{Acknowledgments}

We would like to thank the following experts for their participation in the Delphi process: Dr. Eric Lee, Prof. Joyce You, Miss Tiffany Chan, Dr. Simon So, Dr. Jen-ngai Cheng, Dr. Kwun-man Lo, and Dr. Steven Wong.

Authors' contributions

Study design: HZ, ELW, EKY and BHM. Data collection: HZ and ELW. Data interpretation: $H Z$, ELW, EKY and BHM. Writing of the paper: $\mathrm{HZ}$ and ELW. Revision of the paper: $\mathrm{HZ}$, ELW, EKY and BHM. All authors have seen and approved the final version of the paper for publication. The authors read and approved the final manuscript.

Funding

Not applicable.

Availability of data and materials

All data generated or analyzed during this study are included in this published article and its' supplementary information files.

Ethics approval and consent to participate

The project has been granted ethical approval by the Survey and Behavioral Research Ethics Committee of the Chinese University of Hong Kong (Ref No: SBRE-18-468). All of the participants were given information about the purpose of the study and details of the research procedures before the interview. Written informed consent was obtained from each of the participants before the interview started. The participants were allowed to withdraw from the study at any point. All of the data were kept confidential and anonymous. 


\section{Consent for publication}

Not applicable.

\section{Competing interests}

We declare that we have no conflict of interest.

\section{Author details}

${ }^{1}$ Centre for Health Systems and Policy Research, The Jockey Club School of Public Health and Primary Care, Faculty of Medicine, The Chinese University of Hong Kong, Prince of Wales Hospital, Shatin, New Territories, Hong Kong. ${ }^{2}$ Department of Medicine and Therapeutics, Prince of Wales Hospital, Shatin, New Territories, Hong Kong.

Received: 15 July 2020 Accepted: 13 January 2021

Published online: 02 February 2021

\section{References}

1. Chang C. Bin, Chen JH, wen CJ, Kuo HK, Lu IS, Chiu LS, et al. potentially inappropriate medications in geriatric outpatients with polypharmacy: application of six sets of published explicit criteria. Br J Clin Pharmacol. 2011;72(3):482-9.

2. Hyttinen $\mathrm{V}$, Jyrkkä J, Valtonen $\mathrm{H}$. A systematic review of the impact of potentially inappropriate medication on health care utilization and costs among older adults. Med Care. 2016;54(10):950-64 https://doi.org/10.1097/ MLR.0000000000000587.

3. Kim J. Polypharmacy and medication Management in Older a dults Polypharmacy elderly adverse drug event potentially inappropriate medication. Nurs Clin NA. 2018;52(3):457-68 Available from: https://doi.org/ 10.1016/j.cnur.2017.04.007.

4. Reich O, Rosemann T, Rapold R, Blozik E, Senn O. Potentially inappropriate medication use in older patients in swiss managed care plans: prevalence, determinants and association with hospitalization. PLoS One. 2014;9(8):23-5.

5. Jirón M, Pate V, Hanson LC, Lund JL, Jonsson Funk M, Stürmer T. Trends in prevalence and determinants of potentially inappropriate prescribing in the United States: 2007 to 2012. J Am Geriatr Soc. 2016;64(4):788-97. Available from: http://www.ncbi.nlm.nih.gov/pubmed/27100575\%0A. http://www. pubmedcentral.nih.gov/articlerender.fcgi?artid=PMC4843827.

6. Guaraldo L, Cano FG, Damasceno GS, Rozenfeld S. Inappropriate medication use among the elderly: A systematic review of administrative databases. BMC Geriatr. 2011;11(1):79 Available from: http://www.biomedcentral. com/1471-2318/11/79.

7. Census and Statistics Department. 2017. Population Projections. [ONLINE] Available at: https://www.censtatd.gov.hk/hkstat/sub/sp190 jsp?productCode=B1120015. [Accessed 6 February 2020].

8. United Nations. 2019. World population prospects 2019 Available at: https:// population.un.org/wpp/. [Accessed 9 January 2020].

9. Spinewine A, Schmader KE, Barber N, Hughes C, Lapane KL, Swine C, et al. Prescribing in elderly people 1 appropriate prescribing in elderly people : how well can it be measured and optimised ? 2007;

10. Kaufmann CP, Tremp R, Hersberger KE, Lampert ML. Inappropriate prescribing: A systematic overview of published assessment tools. Vol. 70, Eur J Clin Pharmacol. 2014. p. 1-11.

11. Dimitrow MS, Airaksinen ÃMSA, Kivela ÃS. Comparison of Prescribing Criteria to Evaluate the Appropriateness of Drug Treatment in Individuals Aged 65 and Older: A Systematic Review. J Am Geriatr Soc. 2011;59(8):152130 .

12. Zhan C, Sangl J, Bierman AS, Miller MR, Friedman B, Wickizer SW, et al. Potentially inappropriate medication use in the community-dwelling elderly: findings from the 1996 medical expenditure panel survey. J Am Med Assoc. 2001;286(22):2823-9.

13. Fick DM, Cooper JW, Wade WE, Waller JL, Maclean JR, Beers MH. Updating the Beers criteria for potentially inappropriate medication use in older adults. Arch Intern Med. 2003;163(22):2716.

14. Beers MH, Ouslander JG, Rollingher I, Reuben DB, Brooks J, Beck JC. Explicit criteria for determining inappropriate medication use in nursing home residents. Arch Intern Med. 1991;151(9):1825-32.

15. Fick D, Semla T, Beizer J, Brandt N, Dombrowski R, DuBeau CE, et al. American Geriatrics Society updated Beers Criteria for potentially inappropriate medication use in older adults. Vol. 60, J Am Geriatr Soc. 2012. p. 616-631.
16. Holt S, Schmiedl S, Thurmann PA. Potentially inappropriate medications in the elderly: the PRISCUS list. Dtsch Arztebl Int. 2010;107(31-32):543-U39.

17. Laroche ML, Charmes JP, Merle L. Potentially inappropriate medications in the elderly: a French consensus panel list. Eur J Clin Pharmacol. 2007;63(8): 725-31.

18. Bin CC, Yang SY, Lai HY, Wu RS, Liu HC, Hsu HY, et al. Using published criteria to develop a list of potentially inappropriate medications for elderly patients in Taiwan. Pharmacoepidemiol Drug Saf. 2012;21(12):1269-79.

19. Motter FR, Fritzen JS, Hilmer SN, Paniz ÉV, Paniz VMV. Potentially inappropriate medication in the elderly: a systematic review of validated explicit criteria. Vol. 74, Eur J Clin Pharmacol European Journal of Clinical Pharmacology; 2018. p. 679-700.

20. Gallagher P, Lang PO, Cherubini A, Topinková E, Cruz-Jentoft A, Montero Errasquín $B$, et al. Prevalence of potentially inappropriate prescribing in an acutely ill population of older patients admitted to six European hospitals. Eur J Clin Pharmacol. 2011;67(11):1175-88.

21. Opondo D, Eslami S, Visscher S, de Rooij SE, Verheij R, Korevaar JC, et al. Inappropriateness of medication prescriptions to elderly patients in the primary care setting: a systematic review. PLoS One. 2012;7(8):1-10.

22. McLeod PJ, Huang AR, Tamblyn RM, Gayton DC. Defining inappropriate practices in prescribing for elderly people: a national consensus panel. CMAJ. 1997:156(3):385-91.

23. Rancourt C, Moisan J, Baillargeon L, Verreault R, Laurin D, Grégoire JP. Potentially inappropriate prescriptions for older patients in long-term care. BMC Geriatr. 2004;4:1-9.

24. Lindblad Cl, Hanlon JT, Gross CR, Sloane RJ, Pieper CF, Hajjar ER, et al. Clinically Important Drug-Disease Interactions and Their Prevalence in Older Adults. Clin Ther. 2006;28:8.

25. Winit-Watjana W, Sakulrat P, Kespichayawattana J. Criteria for high-risk medication use in Thai older patients. Arch Gerontol Geriatr. 2008:47(1):3551.

26. Rognstad S, Brekke M, Fetveit A, Spigset O, Wyller TB, Straand J. The Norwegian General Practice (NORGEP) criteria for assessing potentially inappropriate prescriptions to elderly patients. Scand J Prim Health Care. 2009;27(3):153-9 Available from: https://doi.org/10.1080/ 02813430902992215

27. O'Mahony D, O'Sullivan D, Byrne S, O'Connor MN, Ryan C, Gallagher P. STOPP/START criteria for potentially inappropriate prescribing in older people: version 2. Age Ageing. 2015;44(2):213-8.

28. Fick DM, Semla TP, Beizer J, Brandt N, Dombrowski R, Dubeau CE, et al. American Geriatrics Society 2015 updated Beers criteria for potentially inappropriate medication use in older adults. J Am Geriatr Soc. 2015;63(11): 2227-46.

29. Fialová D, Topinková E, Ballokova A, Matejovska-Kubesova H. 2012 CZ expert consensus for potentially inappropriate medication use in old age: appropriate choice of drugs and drug dosing in geriatric patients (section I. ), drug-disease interactions in the old age (section II.). Klin Farmakol a Farm. 2013 Jan 1;27:18-28.

30. Galán Retamal C, Garrido Fernández R, Fernández Espínola S, Ruiz Serrato A, García Ordóñez MA, Padilla MV. Prevalencia de medicación potencialmente inapropiada en pacientes ancianos hospitalizados utilizando criterios explícitos. Farm Hosp. 2014;38(4):305-16.

31. Kim SO, Jang S, Kim CM, Kim YR, Sohn HS. Consensus validated list of potentially inappropriate medication for the elderly and their prevalence in South Korea. Int J Gerontol. 2015;9(3):136-41 Available from: https://doi.org/ 10.1016/j.ijge.2015.05.013.

32. Masnoon N, Shakib S, Kalisch-Ellett L, Caughey GE. Tools for assessment of the appropriateness of prescribing and association with patient-related outcomes: a systematic review. Drugs and Aging. 2018;35(1):43-60 Available from: https://doi.org/10.1007/s40266-018-0516-8.

\section{Publisher's Note}

Springer Nature remains neutral with regard to jurisdictional claims in published maps and institutional affiliations. 